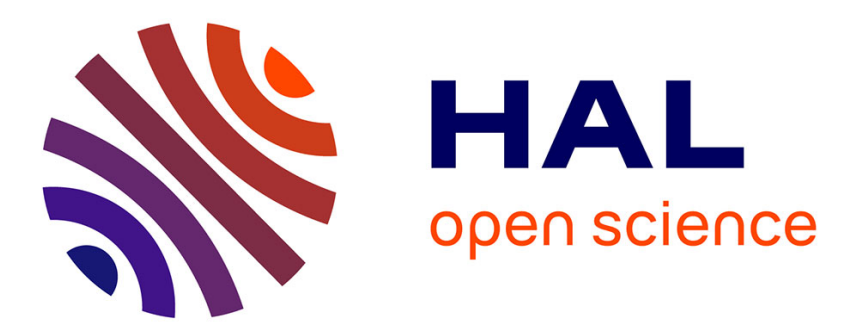

\title{
Somatic mutations in adrenals from patients with primary aldosteronism not cured after adrenalectomy suggest common pathogenic mechanisms between unilateral and bilateral disease
}

Inès Hacini, Kelly de Sousa, Sheerazed Boulkroun, Tchao Meatchi, Laurence Amar, Maria-Christina Zennaro, Fabio Fernandes-Rosa

\section{To cite this version:}

Inès Hacini, Kelly de Sousa, Sheerazed Boulkroun, Tchao Meatchi, Laurence Amar, et al.. Somatic mutations in adrenals from patients with primary aldosteronism not cured after adrenalectomy suggest common pathogenic mechanisms between unilateral and bilateral disease. European Journal of Endocrinology, 2021, 185 (3), pp.405-412. 10.1530/EJE-21-0338 . inserm-03560062

\section{HAL Id: inserm-03560062 https://www.hal.inserm.fr/inserm-03560062}

Submitted on 7 Feb 2022

HAL is a multi-disciplinary open access archive for the deposit and dissemination of scientific research documents, whether they are published or not. The documents may come from teaching and research institutions in France or abroad, or from public or private research centers.
L'archive ouverte pluridisciplinaire HAL, est destinée au dépôt et à la diffusion de documents scientifiques de niveau recherche, publiés ou non, émanant des établissements d'enseignement et de recherche français ou étrangers, des laboratoires publics ou privés. 
Somatic mutations in adrenals from patients with primary aldosteronism not cured after adrenalectomy suggest common pathogenic mechanisms between unilateral and bilateral disease

Inès Hacini ${ }^{1}$, Kelly de Sousa ${ }^{1}$, Sheerazed Boulkroun ${ }^{1}$, Tchao Meatchi ${ }^{1,2}$, Laurence Amar ${ }^{1,3}$, Maria-Christina Zennaro ${ }^{1,4 * \#, ~ F a b i o ~ L ~ F e r n a n d e s-R o s a ~}{ }^{1 * \#}$

1. Université de Paris, PARCC, Inserm. Paris, France

2. Assistance Publique-Hôpitaux de Paris, Hôpital Européen Georges Pompidou, Service d'Anatomie Pathologique, Paris, France

3. Assistance Publique-Hôpitaux de Paris, Hôpital Européen Georges Pompidou, Unité Hypertension artérielle, Paris, France

4. Assistance Publique-Hôpitaux de Paris, Hôpital Européen Georges Pompidou, Service de Génétique, Paris, France

* Equal contribution

\# Corresponding author

Address correspondence to:

Fabio L Fernandes-Rosa, MD, PhD

Inserm, U970

Paris Cardiovascular Research Center - PARCC

56, rue Leblanc,

75015 Paris - France

Tel : +33(0)15398 8043

Fax : + $33(0) 153987952$

e-mail : fabio.fernandes-rosa@inserm.fr

Maria-Christina Zennaro, $\mathrm{MD}, \mathrm{PhD}$

Inserm, U970

Paris Cardiovascular Research Center - PARCC

56, rue Leblanc,

75015 Paris - France

Tel : +33 (0)1 53988042

Fax : + $33(0) 153987952$

e-mail : maria-christina.zennaro@inserm.fr 


\section{Abstract}

Objective: Primary aldosteronism (PA) is the most common form of secondary and curable hypertension. Different germline and somatic mutations are found in aldosterone producing adenoma (APA) and familial forms of the disease, while the causes of bilateral adrenal hyperplasia $(\mathrm{BAH})$ remain largely unknown. Adrenalectomy is the recommended treatment for patients with APA; however, $6 \%$ of patients are not cured and show persistent PA after surgery suggesting BAH. The objective of this study was to analyze clinical data of patients with APA without biochemical success after adrenalectomy as well as the histological and genetic characteristics of their adrenal glands. Design and Methods: Clinical data of 12 patients without biochemical cure were compared to those from 39 PA patients with hormonal cure after surgery. Histological, morphological and genetic characterization of the adrenals was carried out by CYP11B2 and CYP11B1 immunostaining and by CYP11B2-guided NGS. Results: Patients with absent hormonal cure displayed longer duration of arterial hypertension and lower lateralization index of aldosterone production. In 10 patients, APA expressing CYP11B2 were identified. No difference in histological and morphological characteristics was observed between patients with our without hormonal cure. Somatic mutations in APA driver genes were identified in all CYP11B2 positive APA; CACNA1D mutations were the most frequent genetic abnormality. Conclusions: Patients with absent biochemical cure were diagnosed later and exhibited lower lateralization index of aldosterone production, suggesting asymmetric aldosterone production in the context of BAH. Somatic mutations in adrenal glands from those patients indicate common mechanisms underlying BAH and APA. 


\section{Introduction}

Primary aldosteronism (PA) is the most frequent cause of endocrine hypertension, with a prevalence of $\approx 5 \%$ of hypertensive patients in primary care and $10 \%$ to $20 \%$ in reference centers (1-3). PA patients exhibit hypertension associated with high levels of plasma aldosterone, low levels of plasma renin and in some cases hypokalemia. The excessive aldosterone production is attributable in the majority of cases to an unilateral aldosterone producing adenoma (APA) or to a bilateral adrenal hyperplasia (BAH) (4).

In the last decade, different studies identified somatic and germline mutations in genes coding for ion channels and ATPases as responsible for APA and familial forms of PA (5-12). The discovery of these mutations highlighted the central role of calcium signaling in the pathogenesis of the disease (13). Recently, the use of next generation sequencing (NGS) performed on DNA from CYP11B2 positive nodules extracted from formalin fixed paraffin embedded (FFPE) tissues has allowed the identification of somatic heterozygous mutations in KCNJ5 (coding for the potassium channel GIRK4), ATP1Al (coding for the $\alpha 1$ subunit of the $\mathrm{Na}^{+} / \mathrm{K}^{+}$-ATPase), ATP2B3 (coding for the plasma membrane $\mathrm{Ca}^{2+}$-ATPase, type 3 PMCA3), CACNA1D (encoding the Cav1.3 voltage dependent calcium channel), CACNA1H (encoding the Cav3.1 voltage dependent calcium channel), CLCN2 (coding for the chloride channel ClC2), and CTNNB1 (coding for $\beta$-catenin) in more than $88 \%$ of APA (14-17). However, the genetic causes of BAH remain largely unknown. Analysis of 15 adrenals from patients with BAH has shown that BAH may result from the accumulation or enlargement of aldosterone producing cell clusters (APCC) harboring somatic mutations, particularly in the CACNA1D gene (18).

The goal of PA treatment is the normalization of blood pressure, together with correction of hypokalaemia and biochemical abnormalities (aldosterone and renin) in unilateral forms, or the efficient blockade of the mineralocorticoid receptor, since PA is associated with increased risk of cardiovascular complications independently of blood pressure levels (19-23). Surgical 
adrenalectomy is the recommended treatment for lateralized PA $(4,24)$. For this purpose, correct subtyping of PA is mandatory to identify patients with unilateral disease who can be cured after adrenalectomy. Many studies have shown an improvement of hypertension, a decrease in cardiovascular and metabolic risk factors, and a reduction in mortality after adrenalectomy compared with mineralocorticoid receptor antagonist treatment alone (25) (26). Despite the recommendations, approximately $6 \%$ of PA patients classified pre-surgery as having unilateral PA do not achieve complete biochemical cure after adrenalectomy (27). These patients exhibit lower lateralization index on adrenal vein sampling (AVS), suggesting bilateral but asymmetric aldosterone production and a misdiagnosed BAH (28).

The objective of this study was to analyze clinical data of patients with APA without biochemical success after adrenalectomy and to investigate the histological and genetic characteristics of their adrenal glands. 


\section{METHODS}

\section{Patients}

Among patients who underwent adrenalectomy between 2008 and 2018 at the Hôpital Europeen Georges Pompidou recruited within the COMETE-HEGP protocol, 12 patients with partial or absent biochemical cure after adrenalectomy using the PASO criteria (29) were analyzed. Partial biochemical success: correction of hypokalaemia (if present pre-surgery) and a raised aldosterone-to-renin ratio with $\geq 50 \%$ decrease in baseline plasma aldosterone concentration and/or abnormal but improved post-surgery confirmatory test result. Absent biochemical success: persistent hypokalaemia or persistent raised aldosterone-to-renin ratio, or both, with failure to suppress aldosterone secretion with a post-surgery confirmatory test. Data from 39 PA patients with biochemical cure after adrenalectomy and complete clinical, biochemical, histological and genetic exploration (16) were used as controls. The term "non-cured group" used in this article corresponds to patients with partial or absent biochemical success. Seven patients were classified as having absent biochemical success after adrenalectomy and five patients exhibited partial biochemical success (Table S2). All patients exhibited visible adrenal adenoma or adrenal enlargement on CT scan. The study was approved by the French Research ethics committee (Comité de Protection des Personnes, CPP) under authorization number CPP 2012-A00508-35. Written consent has been obtained from each patient or subject after full explanation of the purpose and nature of all procedures used. Methods used for screening and subtype identification of PA were performed according to institutional and Endocrine Society guidelines (4, 30-32). All patients underwent adrenal vein sampling (AVS) to differentiate between unilateral and bilateral aldosterone hypersecretion. AVS sampling was perfomed simultaneously in both adrenal veins and without pharmacologic stimulation $(32,33)$; the complete protocol is described in the supplementary data. Baseline and follow up clinical and 
biochemical characteristics of PA patients without biochemical success after adrenalectomy are described in supplementary tables S1 and S2.

\section{Immunohistochemistry and pathological analysis}

Each paraffined adrenal block from the non cured patients (absent biochemical success) was analysed entirely to have a precise morphological and cellular analysis. Sections (4- $\mu \mathrm{m}$ thick) were deparaffinised in xylene and rehydrated through graded ethanol. Hematoxylin/Eosin, $11 \beta-$ hydroxylase (CYP11B1) and aldosterone synthase (CYP11B2) immunohistochemistry were performed as previously described (16). Images were acquired in a Lamina Slide Scanner from Perkin Elmer and analysed on the Cochin Image Database (Institut Cochin, France). Zona glomerulosa (ZG) hyperplasia was defined as the presence of a continuous character of the ZG, or, in case of discontinuity of the ZG, ZG thickness $\geq 200 \mu \mathrm{m} \quad(16,34)$. CYP11B1 and CYP11B2 staining was quantified as previously described (16). Percentages of aldosteronesynthase and $11 \beta$-hydroxylase expressing cells are reported as: 0 , absent; $1,1 \%-33 \% ; 2,34 \%$ $66 \% ; 3,67 \%-100 \%$.

\section{DNA isolation and sequencing}

Somatic DNA of APA was extracted from fresh frozen tissue (FFT) using QIamp DNA midi kit (Qiagen, Courtaboeuf Cedex, France) and Sanger sequencing targeting hot spot regions of KCNJ5, CACNA1D, ATP1A1, ATP2B3 and CTNNB1 genes was performed as previously described (35). For negative samples on Sanger sequencing and samples not sequenced previously, CYP11B2 immonohistochemistry-guided NGS (CYP11B2 IHC-guided NGS) was performed as previously described (16). Before DNA/RNA extraction of FFPE tissue, APA and aldosterone producing nodules were identified by CYP11B2 IHC. Based on the CYP11B2 IHC, the areas of interest were delimited and isolated for DNA/RNA extraction by scraping unstained FFPE sections guided by the CYP11B2 IHC slide using a scalpel under a Wild Heerbrugg or 
Olympus microscope. DNA was extracted from FFPE sections using AllPrep DNA/RNA FFPE kit (Qiagen). NGS was performed using a NGS kit, covering all coding exons and intron-exon junctions of the KCNJ5 (NM_000890), ATP1A1 (NM_000701), ATP2B3 (NM_0010001344), CTNNB1 (NM_001904), CACNA1D (NM_001128839.2 and NM_000720), APC (NM_000038.5), CACNA1H (NM_021098 and NM_001005407), PRKACA (NM_002730) and ARMC5 (NM_002730) genes (MASTR_PA kit, Multiplicom/Agilent, Santa Clara, CA USA) (16).

\section{Satistical analyses.}

Quantitative variables are reported as medians and interquartile range. Comparisons between groups were done with unpaired t-test when Gaussian distribution or the Mann-Whitney test when no Gaussian distribution. Categorical variables are reported as numbers and and compared with Fisher's exact test. A p value $<0.05$ was considered significant for comparisons between 2 groups. 
Comparison of clinical data between patients with or without biochemical success after adrenalectomy

105

Baseline and follow up clinical and biochemical data are sumarized in Table 1. At follow up (8.5 (interquartile range 4.2,15) months), patients with partial or absent biochemical success exhibited higher systolic $(\mathrm{p}=0.003)$ and diastolic blood pressure $(\mathrm{p}=0.008)$, higher plasma aldosterone levels $(\mathrm{p}<0.0001)$, lower renin levels $(\mathrm{p}=0.007)$, lower plasma $\mathrm{K}^{+}$concentration $(\mathrm{p}<0.0001)$ and higher number of anti hypertensive drugs $(\mathrm{p}=0.003)$ compared with patients with complete biochemical success. The proportion of female patients was lower, but not significative, in the biochemically non-cured group compared with the cured group (16.7\% vs $33 \%, \mathrm{p}=0.47)$. The duration of hypertension before PA diagnosis was longer in patients with absent biochemical success compared with patients with complete biochemical success (11 $(6,15)$ years vs $3(1,8)$ years, $\mathrm{p}=0.002)$. While no differences were observed in pre-operatory plasma aldosterone and plasma renin levels, patients with absent biochemical success displayed a lower lateralization index at AVS ( $\mathrm{p}=0.02)$. No significant differences were found in the other baseline parameters.

\section{Histological analysis}

No difference in the adenoma size was observed between patients with complete biochemical success $(10.5(7,14) \mathrm{mm})$ versus absent biochemical success $(14.5(10,15) \mathrm{mm})$ after adrenalectomy ( $\mathrm{p}=0.09$ ) (Table S3). Zona glomerulosa hyperplasia was observed in 7 out of 12 adrenals from biochemically non-cured PA patients (Table 2). CYP11B2 staining was performed on the entire FFPE blocs of adrenals from biochemically non-cured patients in order to identify aldosterone producing nodules. 10 adrenals showed one CYP11B2 positive adenoma of at least $5 \mathrm{~mm}$ (Table 2). Micronodular hyperplasia was observed in two of these adrenals 
(patients 1 and 4) and CYP11B2 positive secondary micronodules were observed in three adrenals (patients 2, 8 and 9). Aldosterone producing cell clusters (APCCs) were observed in 8 out of 12 adrenals, ranging from 1 to 4 APCCs per adrenal (Table 2). In two adrenals, no adenomas expressing CYP11B2 were observed. The first adrenal (patient 6) exhibited CYP11B2 negative micronodular hyperplasia and three APCCs. In the second adrenal (patient 7) one adenoma non expressing CYP11B2 and two APCCs were observed.

Given the previously documented intratumoral heterogeneity of APA, the number of cells expressing CYP11B2 and CYP11B1 was quantified in each APA (Table 2). Five APAs showed between $67 \%$ and $100 \%$ of cells expressing CYP11B2, two exhibited $33 \%$ to $66 \%$ of cells CYP11B1 (Table S3). FFPE samples from five adenomas without previous sequencing. CACNA1D mutations were identified in three patients (c.1207G>C/p.Gly403Arg, c.2968C>G/p.Arg990Gly, and

\section{Identification of somatic mutations in the absent biochemical success group.}

Among the 10 CYP11B2 positive adenomas from the absent biochemical success group, analysis of hot spot mutations in APA driver genes was performed by Sanger sequencing in fresh frozen adenoma tissue (FFT) from four patients. One somatic KCNJ5 mutation (c.451G>C/p.Gly151Arg) was identified in one adenoma and somatic CACNA1D mutations were identified in three patients: p.Arg990Gly (c.2968C>G), p.Gly403Arg (c.1207G>C), and p.Val1373Asp (c.4117G>A). CYP11B2 IHC-guided NGS was performed in CYP11B2 positive 
153 identified in two patients, and the ATP1A1 mutation p.Leu104Arg ((c.311T $>$ G) was identified

154 in one patient. Targeted NGS was also performed in one CYP11B2 negative adenoma and no 155 mutations in APA driver genes were observed. In total, somatic mutations in APA driver genes 156 were observed in all CYP11B2 expressing adenomas from 12 patients (Table 3).

157 Differently from patients with complete biochemical success after adrenalectomy with a higher 158 prevalence of somatic KCNJ5 mutations (38.4\% within the 39 patients analyzed), CACNA1D 159 mutations were the most prevalent genetic abnormality in APA from patients without 160 biochemical success (60.0\%). Adenomas harbouring CACNA1D mutations (median $9 \mathrm{~mm}$ ) 161 were smaller than adenomas harbouring KCNJ5 mutations (median $14 \mathrm{~mm}$ ) (Table S4). No 162 correlation was observed between the number of CYP11B2 or CYP11B1 expressing cells and 163 the mutation status (Table S4). 
In the present study, we report for the first time the presence of somatic mutations in aldosterone producing nodules from patients with absent biochemical success after adrenalectomy. Analysis of clinical data from 12 PA patients who had undergone adrenalectomy with partial or absent biochemical success after surgery also showed a decreased lateralization index of aldosterone production on AVS but no differences were observed in the histological analysis of CYP11B2 positive adenomas and adrenals from patients completely cured or non-cured after adrenalectomy.

Patients were recruited within a single referral center for hypertension in France and performed histological and genetic characterization of their adrenals. The patients were selected accordingly to an international multicentric consensus for classifying surgical outcome and follow-up of patients with unilateral primary aldosteronism (PASO) (29). This consensus has provided the uniformity of clinical and biochemical criteria of PA outcome in different specialized centres, allowing to identify factors influencing the success of adrenalectomy. We focused this study on patients with unilateral PA who did not reach complete biochemical success after adrenalectomy. These patients could represent a group of patients with a bilateral form of PA misdiagnosed during the AVS, explaining the absence of PA cure after surgery, as suggested by some studies $(28,29)$.

It has been previously shown that younger patients and women displayed a more favourable outcome after adrenalectomy $(29,36-38)$. In the present study, we observed a higher percentage of men among patients with absent biochemical success compared with a previous published cohort of 39 patients with unilateral PA with complete biochemical success after surgery, confirming previous studies. In addition to female sex, other variables were described as predictors for favourable clinical outcome, including short term hypertension ( $\leq 7$ years), 
absence of overweight, low number of antihypertensive drugs, higher baseline blood pressure and no history of diabetes mellitus $(29,37)$. Although we did not observe differences in blood pressure at baseline, number of hypertensive drugs or BMI between patients with or without biochemical success after surgery, biochemically non-cured patients were diagnosed later and presented a longer duration of hypertension. The duration of hypertension may indicate not only a predictor for clinical but also for biochemical outcome of unilateral PA. In the present study, we observed lower lateralization index of aldosterone at AVS in patients without biochemical success. This finding was previously observed in a larger cohort of non-cured PA patients (28), and together with the longer duration of hypertension before PA diagnosis suggests a bilateral disease with asymmetric aldosterone production.

Remarkably, in 10 out of 12 cases, one functional adenoma expressing CYP11B2 was observed in the resected adrenal of patients without biochemical success after adrenalectomy. This finding confirms lateralization of aldosterone production at AVS in the majority of the investigated patients, suggesting asymmetric bilateral aldosterone production; for two patients, no adrenal adenoma expressing CYP11B2 was identified and the source of autonomous and excessive aldosterone production was not identified, suggesting a misdiagnosis of PA subtyping before surgery. Zona glomerulosa hyperplasia as well as heterogeneous CYP11B2 and CYP11B1 expression in APA were observed in the adrenals from non-cured patients, accordingly to previously described adrenals from lateralized PA $(16,39)$. In contrast to a multicentric study of patients with lateralized PA biochemically not-cured after adrenalectomy (28), we did not observe histological findings associated with biochemical success. The absence of relationship between histopathology and biochemical cure was also observed in an Italian cohort of PA patients (40). The difference between these studies may imply differences between patients recruited in different centers, an observation that has already been reported for clinical 
characteristics of patients with PA (35), or may represent less power to identify these

214 differences due to a smaller sample size.

215 Remarkably, we report a high prevalence of somatic mutations in APA driver genes in 216 adenomas from patients with absent biochemical cure. CACNA1D mutations were the most 217 frequent genetic abnormality in APAs from patients with partial or absent success after 218 adrenalectomy, which were not associated with ethnic background as previously reported (15). 219 A higher frequency of somatic $C A C N A 1 D$ mutations was observed previously in the context of 220 bilateral adrenal hyperplasia, with the accumulation or enlargement of APCCs harbouring 221 somatic mutations in APA-driver genes (18), suggesting common pathogenic mechanisms at 222 the origin of BAH and APA. Our data showing the presence of somatic mutations (in particular CACNA1D mutations) in APA from patients not cured after adrenalectomy, also presenting with lower lateralization index and longer duration of HT, support this hypothesis.

Only a small number of APA harboured somatic KCNJ5 mutations, in contrast with what observed in patients with complete biochemical cure in this study and studies analysing a large number of patients from French or European cohorts (16, 35, 41-44). While the small number 228 of KCNJ5 mutations may be associated with the higher number of male patients without biochemical success, the association of KCNJ5 mutations and favourable outcome was described previously, independently from the favourable impact of female sex $(45,46)$. While associations between the mutation status and histological findings are well characterized in APA $(16,47)$, no associations were observed in the present study, probably due to the small 233 number of adenomas within each genotype.

In conclusion, 10 out of 12 adrenals from PA patients without biochemical success after 235 adrenalectomy exhibited CYP11B2 expressing adenomas carrying somatic mutations, 236 confirming the diagnosis of APA. However, these patients were diagnosed later and exhibited 
237 lower lateralization index of aldosterone production at AVS, suggesting asymmetric 238 aldosterone production in the context of BAH. The identification of somatic mutations in 239 adrenal glands from those patients suggests a possible continuum between bilateral and 240 unilateral disease in a subset of patients, supporting common mechanisms underlying BAH and 241 APA.

242

243 Declaration of interest

244 The authors have nothing to disclose

245

246 Acknowledgments

247 The authors wish to thank CE Gomez-Sanchez (University of Mississippi Medical Center, 248 Jackson, MS) for providing antibodies against CYP11B1 and CYP11B2.

\section{Sources of Funding}

250 This work was funded through institutional support from INSERM, the Agence Nationale de la 251 Recherche (ANR-15-CE14-0017-03), and the Fondation pour la Recherche Médicale 252 (DEQ20140329556). 


\section{References}

255 1. Monticone S, Burrello J, Tizzani D, Bertello C, Viola A, Buffolo F, Gabetti L, Mengozzi

G, Williams TA, Rabbia F, et al. Prevalence and Clinical Manifestations of Primary

257

258

259

260

261

262

263

264

265

266

267

268

269

270

271

272

273

274

275

276

277

278

Aldosteronism Encountered in Primary Care Practice. J Am Coll Cardiol. 2017;69(14):181120.

2. Hannemann A, Wallaschofski H. Prevalence of primary aldosteronism in patient's cohorts and in population-based studies--a review of the current literature. Horm Metab Res. 2012;44(3):157-62.

3. Brown JM, Siddiqui M, Calhoun DA, Carey RM, Hopkins PN, Williams GH, Vaidya

A. The Unrecognized Prevalence of Primary Aldosteronism. Ann Intern Med. 2020.

4. Funder JW, Carey RM, Mantero F, Murad MH, Reincke M, Shibata H, Stowasser M, Young WF, Jr. The Management of Primary Aldosteronism: Case Detection, Diagnosis, and Treatment: An Endocrine Society Clinical Practice Guideline. J Clin Endocrinol Metab. 2016;101(5):1889-916.

5. Choi M, Scholl UI, Yue P, Bjorklund P, Zhao B, Nelson-Williams C, Ji W, Cho Y, Patel $\mathrm{A}$, Men $\mathrm{CJ}$, et al. $\mathrm{K}+$ channel mutations in adrenal aldosterone-producing adenomas and hereditary hypertension. Science. 2011;331(6018):768-72.

6. Beuschlein F, Boulkroun S, Osswald A, Wieland T, Nielsen HN, Lichtenauer UD, Penton D, Schack VR, Amar L, Fischer E, et al. Somatic mutations in ATP1A1 and ATP2B3 lead to aldosterone-producing adenomas and secondary hypertension. Nat Genet. 2013;45(4):440-4, 4e1-2.

7. Scholl UI, Goh G, Stolting G, de Oliveira RC, Choi M, Overton JD, Fonseca AL, Korah R, Starker LF, Kunstman JW, et al. Somatic and germline CACNA1D calcium channel mutations in aldosterone-producing adenomas and primary aldosteronism. Nat Genet. 2013;45(9):1050-4. 
279 8. Azizan EA, Poulsen H, Tuluc P, Zhou J, Clausen MV, Lieb A, Maniero C, Garg S, 280 Bochukova EG, Zhao W, et al. Somatic mutations in ATP1A1 and CACNA1D underlie a 281 common subtype of adrenal hypertension. Nat Genet. 2013;45(9):1055-60.

282 9. Fernandes-Rosa FL, Daniil G, Orozco IJ, Goppner C, El Zein R, Jain V, Boulkroun S, 283 Jeunemaitre X, Amar L, Lefebvre H, et al. A gain-of-function mutation in the CLCN2 chloride 284 channel gene causes primary aldosteronism. Nat Genet. 2018;50(3):355-61.

285 10. Scholl UI, Stolting G, Schewe J, Thiel A, Tan H, Nelson-Williams C, Vichot AA, Jin 286 SC, Loring E, Untiet V, et al. CLCN2 chloride channel mutations in familial 287 hyperaldosteronism type II. Nat Genet. 2018;50(3):349-54.

288 11. Dutta RK, Arnesen T, Heie A, Walz M, Alesina P, Soderkvist P, Gimm O. A somatic 289 mutation in CLCN2 identified in a sporadic aldosterone-producing adenoma. Eur J Endocrinol. $290 \quad 2019 ; 181(5): K 37-K 41$.

291 12. Nanba K, Blinder AR, Rege J, Hattangady NG, Else T, Liu CJ, Tomlins SA, Vats P, 292 Kumar-Sinha C, Giordano TJ, et al. Somatic CACNA1H Mutation As a Cause of Aldosterone293 Producing Adenoma. Hypertension. 2020;75(3):645-9.

294 13. Zennaro MC, Boulkroun S, Fernandes-Rosa FL. Pathogenesis and treatment of primary 295 aldosteronism. Nat Rev Endocrinol. 2020;16(10):578-89.

296 14. Nanba K, Omata K, Else T, Beck PCC, Nanba AT, Turcu AF, Miller BS, Giordano TJ, 297 Tomlins SA, Rainey WE. Targeted Molecular Characterization of Aldosterone-Producing 298 Adenomas in White Americans. J Clin Endocrinol Metab. 2018;103(10):3869-76.

299 15. Nanba K, Omata K, Gomez-Sanchez CE, Stratakis CA, Demidowich AP, Suzuki M, 300 Thompson LDR, Cohen DL, Luther JM, Gellert L, et al. Genetic Characteristics of Aldosterone301 Producing Adenomas in Blacks. Hypertension. 2019;73(4):885-92. 
Douriez I, Meatchi T, Amar L, et al. Genetic, Cellular, and Molecular Heterogeneity in

Adrenals With Aldosterone-Producing Adenoma. Hypertension. 2020;75(4):1034-44.

17. Nanba K, Yamazaki Y, Bick N, Onodera K, Tezuka Y, Omata K, Ono Y, Blinder AR, Tomlins SA, Rainey WE, et al. Prevalence of Somatic Mutations in Aldosterone-Producing Adenomas in Japanese Patients. J Clin Endocrinol Metab. 2020;105(11).

18. Omata K, Satoh F, Morimoto R, Ito S, Yamazaki Y, Nakamura Y, Anand SK, Guo Z, Stowasser M, Sasano H, et al. Cellular and Genetic Causes of Idiopathic Hyperaldosteronism. Hypertension. 2018;72(4):874-80.

19. Catena C, Colussi G, Nadalini E, Chiuch A, Baroselli S, Lapenna R, Sechi LA. Cardiovascular outcomes in patients with primary aldosteronism after treatment. Arch Intern Med. 2008;168(1):80-5.

20. Milliez P, Girerd X, Plouin PF, Blacher J, Safar ME, Mourad JJ. Evidence for an increased rate of cardiovascular events in patients with primary aldosteronism. J Am Coll Cardiol. 2005;45(8):1243-8.

21. Savard S, Amar L, Plouin PF, Steichen O. Cardiovascular complications associated with primary aldosteronism: a controlled cross-sectional study. Hypertension. 2013;62(2):331-6.

22. Reincke M, Fischer E, Gerum S, Merkle K, Schulz S, Pallauf A, Quinkler M, Hanslik G, Lang K, Hahner S, et al. Observational study mortality in treated primary aldosteronism: the German Conn's registry. Hypertension. 2012;60(3):618-24.

23. Wu VC, Wang SM, Chang CH, Hu YH, Lin LY, Lin YH, Chueh SC, Chen L, Wu KD. Long term outcome of Aldosteronism after target treatments. Sci Rep. 2016;6:32103.

24. Amar L, Baguet JP, Bardet S, Chaffanjon P, Chamontin B, Douillard C, Durieux P, Girerd X, Gosse P, Hernigou A, et al. SFE/SFHTA/AFCE primary aldosteronism consensus: Introduction and handbook. Ann Endocrinol (Paris). 2016;77(3):179-86. 
25. Sukor N, Kogovsek C, Gordon RD, Robson D, Stowasser M. Improved quality of life, blood pressure, and biochemical status following laparoscopic adrenalectomy for unilateral primary aldosteronism. J Clin Endocrinol Metab. 2010;95(3):1360-4.

26. Lin YH, Wu XM, Lee HH, Lee JK, Liu YC, Chang HW, Lin CY, Wu VC, Chueh SC, Lin LC, et al. Adrenalectomy reverses myocardial fibrosis in patients with primary aldosteronism. J Hypertens. 2012;30(8):1606-13.

27. Muth A, Ragnarsson O, Johannsson G, Wangberg B. Systematic review of surgery and outcomes in patients with primary aldosteronism. Br J Surg. 2015;102(4):307-17.

F, Kline GA, Knosel T, et al. Immunohistopathology and Steroid Profiles Associated With

Biochemical Outcomes After Adrenalectomy for Unilateral Primary Aldosteronism. Hypertension. 2018;72(3):650-7.

29. Williams TA, Lenders JWM, Mulatero P, Burrello J, Rottenkolber M, Adolf C, Satoh

F, Amar L, Quinkler M, Deinum J, et al. Outcomes after adrenalectomy for unilateral primary aldosteronism: an international consensus on outcome measures and analysis of remission rates in an international cohort. Lancet Diabetes Endocrinol. 2017;5(9):689-99.

30. Letavernier E, Peyrard S, Amar L, Zinzindohoue F, Fiquet B, Plouin PF. Blood pressure outcome of adrenalectomy in patients with primary hyperaldosteronism with or without unilateral adenoma. J Hypertens. 2008;26(9):1816-23.

31. Funder JW, Carey RM, Fardella C, Gomez-Sanchez CE, Mantero F, Stowasser M, Young WF, Jr., Montori VM, Endocrine S. Case detection, diagnosis, and treatment of patients with primary aldosteronism: an endocrine society clinical practice guideline. J Clin Endocrinol Metab. 2008;93(9):3266-81. 
chromatography-tandem mass spectrometry determinations of plasma aldosterone concentration. J Hypertens. 2018;36(7):1592-601.

33. Kupers EM, Amar L, Raynaud A, Plouin PF, Steichen O. A clinical prediction score to diagnose unilateral primary aldosteronism. J Clin Endocrinol Metab. 2012;97(10):3530-7.

34. Lack EE. Tumors of the adrenal gland and extra-adrenal paraganglia. In: Pathology ARo, editor. Atlas of Tumor Pathology. Series 42007.

35. Fernandes-Rosa FL, Williams TA, Riester A, Steichen O, Beuschlein F, Boulkroun S, Strom TM, Monticone S, Amar L, Meatchi T, et al. Genetic spectrum and clinical correlates of somatic mutations in aldosterone-producing adenoma. Hypertension. 2014;64(2):354-61.

36. Steichen O, Zinzindohoue F, Plouin PF, Amar L. Outcomes of adrenalectomy in patients with unilateral primary aldosteronism: a review. Horm Metab Res. 2012;44(3):221-7.

37. Morisaki M, Kurihara I, Itoh H, Naruse M, Takeda Y, Katabami T, Ichijo T, Wada N, Yoshimoto T, Ogawa Y, et al. Predictors of Clinical Success After Surgery for Primary Aldosteronism in the Japanese Nationwide Cohort. J Endocr Soc. 2019;3(11):2012-22.

38. Rossi GP, Rossitto G, Amar L, Azizi M, Riester A, Reincke M, Degenhart C, Widimsky J, Jr., Naruse M, Deinum J, et al. Clinical Outcomes of 1625 Patients With Primary Aldosteronism Subtyped With Adrenal Vein Sampling. Hypertension. 2019;74(4):800-8.

39. Boulkroun S, Samson-Couterie B, Dzib JF, Lefebvre H, Louiset E, Amar L, Plouin PF, Lalli E, Jeunemaitre X, Benecke A, et al. Adrenal cortex remodeling and functional zona glomerulosa hyperplasia in primary aldosteronism. Hypertension. 2010;56(5):885-92.

40. Citton M, Viel G, Rossi GP, Mantero F, Nitti D, Iacobone M. Outcome of surgical treatment of primary aldosteronism. Langenbecks Arch Surg. 2015;400(3):325-31.

41. Boulkroun S, Beuschlein F, Rossi GP, Golib-Dzib JF, Fischer E, Amar L, Mulatero P, Samson-Couterie B, Hahner S, Quinkler M, et al. Prevalence, clinical, and molecular correlates of KCNJ5 mutations in primary aldosteronism. Hypertension. 2012;59(3):592-8. 
Robinson B, Iwen KA, Dralle H, et al. Novel somatic mutations and distinct molecular signature

379 in aldosterone-producing adenomas. Endocr Relat Cancer. 2015;22(5):735-44.

43. Scholl UI, Healy JM, Thiel A, Fonseca AL, Brown TC, Kunstman JW, Horne MJ,

Dietrich D, Riemer J, Kucukkoylu S, et al. Novel somatic mutations in primary hyperaldosteronism are related to the clinical, radiological and pathological phenotype. Clin Endocrinol (Oxf). 2015;83(6):779-89. of Somatic KCNJ5 K(+) Channel Mutations In 1636 Patients With an Aldosterone-Producing Adenoma. J Clin Endocrinol Metab. 2015;100(8):E1089-95.

45. Vilela LAP, Rassi-Cruz M, Guimaraes AG, Moises CCS, Freitas TC, Alencar NP, Petenuci J, Goldbaum TS, Maciel AAW, Pereira MAA, et al. KCNJ5 Somatic Mutation Is a Predictor of Hypertension Remission After Adrenalectomy for Unilateral Primary Aldosteronism. J Clin Endocrinol Metab. 2019;104(10):4695-702.

46. Kitamoto T, Omura M, Suematsu S, Saito J, Nishikawa T. KCNJ5 mutation as a 392 predictor for resolution of hypertension after surgical treatment of aldosterone-producing 393 adenoma. J Hypertens. 2018;36(3):619-27.

47. Ono Y, Yamazaki Y, Omata K, Else T, Tomlins SA, Rhayem Y, Williams TA, Reincke 
Table 1. Baseline and follow up clinical and biochemical data of PA patients with or without biochemical success after adrenalectomy.

Non biochemical success

(12)

Biochemical success (39) p value

\begin{tabular}{|c|c|c|c|}
\hline Age (ys) & $47(39,51)$ & $44(35,50)$ & 0.90 \\
\hline Gender F/M (F\%) & $2 / 10(16.7 \%)$ & $13 / 26(33.3 \%)$ & 0.03 \\
\hline BMI (kg/m2) & $31.2(29,35)$ & $28.5(25,33)$ & 0.182 \\
\hline HT duration (ys) & $12(6,15)$ & $3(1,8)$ & 0.0022 \\
\hline \multicolumn{4}{|l|}{ Pre-op parameters } \\
\hline Aldosterone (pmol/L) & $1049(530,1436)$ & $883.5(569,1254)$ & 0.71 \\
\hline $\operatorname{Renin}(\mathrm{mU} / \mathrm{L})$ & $1.15(1,2.75)$ & $1.0(1,2.075)$ & 0.39 \\
\hline ARR & $209(106,287)$ & $168(109,234)$ & 0.58 \\
\hline $\mathrm{K}+(\mathrm{mmol} / \mathrm{L})$ & $2.8(2.5,3.1)$ & $2.8(2.5,3.1)$ & 0.95 \\
\hline $\mathrm{SBP}(\mathrm{mmHg})$ & $157(144,163)$ & $146(138,152)$ & 0.06 \\
\hline $\mathrm{DBP}(\mathrm{mmHg})$ & $94(88,98)$ & $90(83,96)$ & 0.51 \\
\hline Lateralization Index & $6.3(5,10)$ & $15(8,26)$ & 0.02 \\
\hline Antihipertensive drugs $(\mathrm{N})$ & $2.5(2,3)$ & $2(2,3)$ & 0.37 \\
\hline \multicolumn{4}{|l|}{ Follow up } \\
\hline Aldosterone (pmol/L) & $445.8(333,487)$ & $124.9(80,168)$ & $<0.0001$ \\
\hline $\operatorname{Renin}(\mathrm{mU} / \mathrm{L})$ & $1.8(1.1,3.7)$ & $9.6(7,13)$ & $<0.0001$ \\
\hline ARR & $73(67,103)$ & $16(9.4,23)$ & $<0.0001$ \\
\hline $\mathrm{K}+(\mathrm{mmol} / \mathrm{L})$ & $3.4(3.1,3.9)$ & $4.1(3.7,4.3)$ & $<0.0001$ \\
\hline $\mathrm{SBP}(\mathrm{mmHg})$ & $147(142,157)$ & $129(116,134)$ & 0.003 \\
\hline $\mathrm{DBP}(\mathrm{mmHg})$ & $93.9(89,96)$ & $83.7(79,86)$ & 0.008 \\
\hline Antihipertensive drugs & $1(1,3)$ & $0(0,1)$ & 0.003 \\
\hline
\end{tabular}

Ys: years; F: female, M: male; BMI: body mass index; HT: hypertension; ARR; Aldosterone to renin ratio; SBP: systolic blood pressure, DBP: diastolic blood pressure. Values are expressed as median (interquartile range). 
Table 2 Histological characteristics of adrenals from non-cured PA patients

\begin{tabular}{|c|c|c|c|c|c|}
\hline Patient & $\begin{array}{l}\text { CYP11B2 }^{+} \text {adenoma } \\
\text { size }(\mathrm{mm})\end{array}$ & $\operatorname{APCC}(\mathrm{N})$ & $\begin{array}{c}\mathrm{ZG} \\
\text { hyperplasia }\end{array}$ & $\begin{array}{l}\text { CYP11B2 expression } \\
\text { (\% of positive cells) } \downarrow\end{array}$ & $\begin{array}{l}\text { CYP11B } 1 \text { expression } \\
\text { (\% of positive cells) }\end{array}$ \\
\hline 1 & 25 & 0 & $\mathrm{Y}$ & 1 & 2 \\
\hline 2 & 7 & 0 & $\mathrm{Y}$ & 3 & 1 \\
\hline 3 & 8 & 0 & Y & 3 & 1 \\
\hline 4 & 11 & 3 & $\mathrm{Y}$ & 1 & 1 \\
\hline 5 & 5 & 0 & $\mathrm{Y}$ & 1 & 2 \\
\hline $6^{*}$ & No & 3 & $\mathrm{Y}$ & - & - \\
\hline $7 * *$ & No & 2 & $\mathrm{~N}$ & - & - \\
\hline 8 & 10 & 3 & $\mathrm{~N}$ & 2 & 1 \\
\hline 9 & 14 & 2 & $\mathrm{~N}$ & 3 & 1 \\
\hline 10 & 10 & 4 & $\mathrm{~N}$ & 2 & 1 \\
\hline 11 & 15 & 1 & $\mathrm{Y}$ & 3 & 1 \\
\hline 12 & 11 & 4 & $\mathrm{~N}$ & 3 & 1 \\
\hline
\end{tabular}

* Micronodular hyperplasia non expressing CYP11B2. **nodule $12 \mathrm{~mm}$ non expressing CYP11B2. $\ddagger 1$ : 1\%-33\%; 2: 34\%-66\%; 3: 67\%-100\%. APCC: aldosterone producing cell clusters; ZG: zona glomerulosa; Y: yes; N: no. 
Table 3. Genetic analysis of CYP11B2 positive APAs from PA patients without biochemical success after adrenalectomy

\begin{tabular}{|c|c|c|c|c|c|c|}
\hline APA & $\begin{array}{c}\text { Gene mutated } \\
\text { Sanger sequencing }\end{array}$ & $\begin{array}{c}\text { Gene mutated } \\
\text { NGS }\end{array}$ & Read depth & VAF & Nucleotide & Protein \\
\hline 1 & KCNJ5 & - & - & - & c. $451 \mathrm{G}>\mathrm{C}$ & p.Gly151Arg \\
\hline 2 & $C A C N A 1 D$ & - & - & - & c. $2968 \mathrm{C}>\mathrm{G}$ & p.Arg990Gly \\
\hline 3 & CACNAID & - & - & - & c. $1207 \mathrm{G}>\mathrm{C}$ & p.Gly403Arg \\
\hline 4 & - & KCNJ5 & 1044 & $28 \%$ & c. $451 \mathrm{G}>\mathrm{C}$ & p.Gly151Arg \\
\hline 5 & CACNAID & - & - & - & c. $4117 \mathrm{G}>\mathrm{A}$ & p.Val1373Asp \\
\hline 8 & - & $C A C N A 1 D$ & 2384 & $15 \%$ & c. $1207 \mathrm{G}>\mathrm{C}$ & p.Gly403Arg \\
\hline 9 & - & KCNJ5 & 1044 & $28 \%$ & c. $451 \mathrm{G}>\mathrm{C}$ & p.Gly151Arg \\
\hline 10 & - & $A T P 1 A 1$ & 625 & $17 \%$ & c. $311 \mathrm{~T}>\mathrm{G}$ & p.Leu104Arg \\
\hline 11 & - & CACNA1D & 1871 & $33 \%$ & c. $3458 \mathrm{~T}>\mathrm{A}$ & p.Val1153Asn \\
\hline 12 & - & CACNAID & 646 & $27 \%$ & c. $2968 C>G$ & p.Arg990Gly \\
\hline
\end{tabular}

NGS; next generation sequencing. VAF, Variant Allele Frequency. KCNJ5 (NM_000890), ATP1A1 (NM_000701), CACNA1D (NM_001128839.2 and NM_000720).

399

400 